\title{
Internationalized Talents Cultivation of Yunnan and South-Asia Propelled by Joint Efforts of Government, University and
}

\section{Enterprise-On International Exchange and Cooperation Among Yunnan and South-Asia Under “The Belt and Road Initiative”}

\author{
Zhu Yaoshun, Li Shunqin*, Yun Jianhui, Chen Liang \\ Yunnan Agricultural University, Kunming, China
}

\begin{abstract}
"The Belt and Road Initiative" needs internationalized talents. To deepen the international cooperation of higher education with South-Asia countries depends on the cooperation and joint efforts from government, universities, and enterprises, which aimed at promoting internationalized talents' development. What's more, they should verify their responsibilities and strengthen their relationships and connects, jointly improving international talents cultivation of Yunnan and South-Asia countries. Therefore, more high quality talents with high identity for "The Belt and Road Initiative” will be cultivated, which will promote the economic development of Yunnan province and South-Asia countries.
\end{abstract}

Keywords: higher education, South Asia, internationalization, talents cultivation, international cooperation

\section{Introduction}

Development is an important theme in 21th century. Harmonious development of the world is expected. Nowadays, countries link more and more closer in economy. "The Belt and Road Initiative” meets the demand of world's harmonious development, and it needs internationalized talents. To deepen the international cooperation of higher education with South-Asia countries depends on the cooperation and joint efforts from government, universities and enterprises, which aimed at promoting internationalized talents' development. What's more, they should verify their responsibilities and strengthen their relationships and connects, jointly improving international talents cultivation of Yunnan and South-Asia countries. Therefore, more high quality talents with high identity for "The Belt and Road Initiative" will be cultivated, which will promote the

Funding Program: Result of "International Regime on Higher Education Cooperation between Yunnan Province and South-East Countries Asia Countries” from Yunnan Agricultural University Project. (Project Code: 2015SK10)

Zhu Yaoshun, associate professor, Ph.D. student, Dean’s office, International College, Yunnan Agricultural University, Kunming, China.

Li Shunqin*, corresponding author, lecturer, Overseas Students Affairs’ office, International College, Yunnan Agricultural University, Kunming, China.

Yun Jianhui, lecturer, Overseas Students Affairs’ office, International College, Yunnan Agricultural University, Kunming, China.

Chen Liang, teaching assistant, Overseas Students Affairs' office, International College, Yunnan Agricultural University, Kunming, China.

Correspondence concerning this article should be addressed to Li Shunqin, Overseas Students Affairs' office, International College, Yunnan Agricultural University, No. 452 Fengyuan Road, Panlong District, Kunming 650201, Yunnan, China. 
economic development of Yunnan province and South-Asia countries.

\section{Literature Review}

China has a long history of friendly cooperation with South-Asia countries. South-Asia is the junction area of ocean and land of "The Belt and Road Initiative" and of "China-Pakistan Economic Corridor" and "China-India-Myanmar Economic Corridor". It is also a crucial component of "The Belt and Road Initiative" (Lou, 2015). Yunnan is the gate of Southwest China and frontier of China that faces South and South-East Asia. Because of its unique geographical location, Yunnan is more closed with South-Asia in cooperation and shares more cooperative space. Think tank and talents should be the prerequisite of economic development. Thus, Yunnan is faced with both opportunities and challenges in higher education exchange and cooperation. "Today, internationalization of higher education is not limited to a geographical interpretation of the concept”. (Knight, 1999) In recent years, Yunnan puts more efforts to its exchange and cooperation among South-Asia countries and currently Yunnan is exploring a new passage for cultivating internationalized talents for Yunnan's higher education in "The Belt and Road Initiative". It must have value both theoretically and practically crucial to analyze and consider thoroughly on international exchange and cooperation in higher education between Yunnan province and South-Asia countries, and to make recommendation to leadership.

\section{The Relationship Among Politics, Economy, and Culture}

Being three basic spheres in social life, politics, economy, and culture affect and restrict one another, in which economy is the base and politics will represent economy. Also, economy and politics determine culture, and culture represents economy and politics. In the meantime, culture will counteract on economy and politics and exert influence on them.

"The Belt and Road Initiative" is a political policy and the main purpose is to develop economy. But the implementation of this strategy depends on the development of culture. Talents cultivation and construction of think tank are important components of cultural development.

Director Wang Huiyao emphasizes the importance of talents cultivation and construction of think tank for "The Belt and Road Initiative”. The construction of think tank should develop for realizing "The Belt and Road Initiative”. And international think tanks should establish channels and platforms for discussion, also the think tanks should establish platforms for scholars. (Zhang, 2015)

The regional economic development of Yunnan requires cultivation of internationalized talents and exchange and cooperation of higher education is an essential way to realize internationalized higher education. "The Belt and Road Initiative" will improve internationalized higher education of China (Bai, 2015). Higher education in China and South-Asia countries need to foster internationalized talents and provide intellectuals and talents for "The Belt and Road Initiative" and improve the economic develop in China and South-Asia countries.

\section{Internationalized Talents Cultivation of Yunnan and South-Asia by Government, University, and Enterprise}

Nowadays, internationalization of higher education is so important and necessary that "governments emphasize on internationalization of higher education through international co-operation and exchange" and "Institutions and universities develop their own strategies to internationalize their researches and their teaching” 
(Akbar Zolfaghari, Sabran, \& Ali Zolfaghari, 2009). In the background of globalization, "Internationalized education is the commend need of Yunnan and South-Asia” (Zhu, Fan, \& Li, 2015). According to Chen and Weng (2015), "internationalized higher education in China should be oriented at serving needs of national economy and social development. Also, it should explore international business and cultivate talents with international competitiveness". The core of internationalized education is internationalized talents cultivation. Fostering Chinese talents should be given priority in cultivating talents for Yunnan and South-Asia, and international students should be included. The cultivating process requires cooperation of government, universities, and enterprises. And they should accomplish their own jobs, communicate with each other, and strengthen their relations, promoting talents cultivation of Yunnan and South-Asia countries. Finally, international talents will be cultivated with high quality and sense of identity, providing intellectual support for bilateral economic development of Yunnan and South-Asia countries.

\section{The Responsibilities of Government: Macro-Guidance, Overall Coordination, and Good Service}

Macro-guidance. The government can give macro-guidance to the exchange and cooperation among Yunnan and South-Asia countries of higher education through policies, such as more supports from policies, simplified administrative procedures. Also, it can increase the amount of scholarship to attract more international students and in the meanwhile government can promote more Chinese academically excellent students to study overseas, such IT majors in India, thus improving the quality overseas education. Besides, the government can boost scientific research by funding research in exchange and cooperation of among Yunnan and South-Asia countries.

Overall coordination. If the government can establish contact between higher education institutes and companies, and build communication mechanism between department of culture and education and companies, this will improve mutual development.

The educational administrative departments shall coordinate research in exchange and cooperation among Yunnan and South-Asia countries. Surrounded by "The Belt and Road Initiative", the government should deeply study relative research subjects, especially strengthen research among Yunnan and South-Asia countries, realize development of higher education in South-Asia countries, and be familiar with advantages of both sides. Based on those information and current research results, the government should analyze the talents needs for implementing "The Belt and Road Initiative", scientifically plan sustainable development for the exchange and cooperation, finally realizing development with overall aspects, steps, priorities, and multiple levels, providing talents for development of both sides.

Good service. The government should provide high-quality service for exchange and cooperation among Yunnan and South-Asia countries, and platforms and channels for cooperation.

The government can establish joint information bank of universities in Yunnan and realize the communication and share of information and resources among Yunnan and South-Asia countries. The Embassy and Consulate-level connection among Yunnan and South-Asia countries should be built to improve sustainable development of educational exchange and cooperation. Also, through Yunnan and South-Asia Expo, the educational cooperation and exchange of higher education will be improved. At the same time, universities in South-Asia countries are welcome to introduce their higher education institutes and promote related information of Yunnan Province to South-Asia countries via this platform. The government should hold international educational expo in South-Asia countries and attract more students there to study in Yunnan via 
various types of scholarships.

Yunnan Provincial Department of Education should actively promote the establishment of "Universities Union" of "The Belt and Road" countries, and they should consider establishing Universities Union among Yunnan and South-Asia countries. Therefore, it can fully take advantage of Yunnan's higher education and combine their advantages with universities in South-Asia countries, thus fostering international talents and promoting the development of higher education in Yunnan and South-Asia countries.

\section{The Responsibilities of Universities: In-depth Research, High Level, Strengthened Cooperation, and Coordinated Innovation}

Research deeply. Universities and research institutes need to find the opportunities for cooperation in their fields. And they should consider the common and different aspects of South-Asia countries, make diversified curriculum for students in different majors to improve the development of Yunnan and South-Asia countries.

Level improved. Universities and research institutes should continue researching in their fields and promote their international reputation and influence, thus improving their ability in international cooperation and exchange, and attracting more international students.

Cooperation strengthened. Universities in Yunnan can take different initiatives to take part in exchange and cooperation among Yunnan and South-Asia countries.

(1) Exchange and cooperation in international research programs

Based on their research level, universities in Yunnan should cooperate with universities in South-Asia countries in scientific research, and foster high-quality talents through researches and cultivate international talents jointly.

(2) Diversified talents cultivation methods

Taking advantages of regional education of both sides, universities in Yunnan can take measures like joint-cultivation, international students, distance education, and "one-on-one" to boost economic development of both sides. For example, Yunnan and Maldives both have rich tourism resources and need talents in tourism, therefore they can jointly cultivate talents in tourism and reasonably distribute resources of both sides through institutes such as Tourism and Education Joint Union. Besides, India has some world-class universities in Science and Engineering, so they can try deep cooperation with Yunnan and improve the higher education of Yunnan. Higher education institute in agriculture, due to its unbalanced higher education institutes, shares a small percentage in India. Agricultural people account for $70 \%$ of its total population, therefore the lack of agricultural talents will impede its agriculture at some degree. Yunnan is the Kingdom of animals and plants with distinctive advantages in resources, so it has more balanced programs structure in agriculture, even some of which are of world-class (Chen, 2006). Therefore, some universities can cooperate with India in cultivating agricultural talents and improve its agricultural higher education. Also, the Internet should be widely used in searching the feasibility and opening in higher education. Statistics of 2013 have shown that Yunnan Open University has signed MOAs with 11 universities in eight South-Asia countries (Ran, 2013). So, the course of internationalization of higher education has been accelerated by Internet.

"One-on-One”: Universities in Yunnan, using their own advantages in different disciplines, cooperate with one of universities in South-Asia. Comprehensive universities, agricultural universities, economic universities, normal universities, medical universities, and engineering universities can find their partner universities in 
South-Asia and develop cooperation and exchange with long term, depth, and all perspectives.

(3) "Bringing in" and "Going out"

Exchange and cooperation among experts, scholars, and international students should adopt both "bringing in" and "going out". By means of international conference and international education expo, universities can strengthen their cooperation and exchange. They can both bring in experts, scholars, and international students from South-Asia countries, and send experts, scholars, and international students of Yunnan to South-Asia. Through friendly cooperation, universities of both sides can improve their cultural visits, strengthen mutual understanding and identity, and cultivate internationalized view and finally promote the higher education.

Coordinated innovation. In recent years, many universities would choose a new path that combines producing, teaching, and research, by which universities develop coordinately with companies. The author believes that this method is suitable for Yunnan in cultivating international talents. Since innovation is essential in thinking, technology, and cooperation, internationalized talents of innovation would definitely boost the course of cooperation.

It is necessary that universities should innovate cultivation mode of international talents and establish a cultivation mode with multiple subjects (government, universities, and enterprises). The current predicament is solely supported by universities with less favors from government and society. Universities should change the situation and combine resources of government, universities, and society and compliment with one another. (Duan \& Li, 2014)

\section{The Responsibilities of Enterprises: Valued Human Resources, Feedback, Cooperation of Universities, and Enterprises}

Valued human resources. It is acknowledged that excellent enterprises need human resources to internationalize themselves. According to European countries and America, "the competition for skilled human resources between European higher education institutions (HEI) through a multi-level model predicting their ability to attract foreign researchers” (Lepori, Seeber, \& Bonaccorsi, 2015). The economic development of Yunnan towards South-Asia depends on a bunch of internationalized enterprises in two aspects: (1) improve companies by foreign scholars in the process of international cooperation and exchange; and (2) enterprises can, according to their needs, make requirements for talents cultivation to universities to store more human resources.

Information feedback. In the process of economic cooperation of enterprises of Yunnan and South-Asia countries, there is an increasing need for more talents and qualified talents. Therefore, the combination of talents cultivation and market needs is the trend for talents cultivation in universities. Universities and enterprises should establish an information mechanism to reflect the needs of them for talents. This is not only the need for development of universities but also for higher education. Through cooperation among universities and enterprises, they can achieve mutual benefits and win-win. Also, universities can connect directly with enrollment department in universities and offer suggestions to them to improve their internationalization.

Cooperation between universities and enterprises. There is an increasing need for quality of talents for the development and bloom of economy among Yunnan and South-Asia countries. Enterprises should coordinate with universities to solve research and technological problems together; with more high quality talents, they can cultivate more talents objectively. For the need of long-term economic development with South-Asia countries, enterprises can make order-style cultivation requirements for universities and foster them 
as needed.

\section{Conclusion}

"The Belt and Road Initiative" needs more higher education institutes to join the cultivation for international talents and it's both a challenge and opportunity for universities in Yunnan. To deepen international cooperation and exchange with South-Asia, countries need joint effort from government, universities, and enterprises. And they should verify their responsibilities and strengthen their relationships. The government should give macro guidance, coordination, and good service; universities should conduct more in-depth researches, improve their level, strengthen Cooperation, and coordinate innovation; enterprises should value human resources, feedback actively, and join in cooperation with universities actively. With efforts from three parties, they can promote the cultivation of international talents. Therefore, they can provide more high quality talents with high identity for "The Belt and Road Initiative" and supply talents for the economic development of Yunnan and South-Asia countries.

\section{References}

Zolfaghari, Akbar, Sabran, M. S., \& Zolfaghari, Ali (2009). Internationalization of higher education: Challenges, strategies, policies and programs. US-China Education Review, 54(5), 1-8.

Bai, L. (2015). Discussion on methods of internationalization of higher education led by “The Belt and Road Initiative”. New West, 3, 121-125.

Chen, C. G., \& Weng, L. X. (2015). Internationalization of higher education and creative talents cultivation. Road to Success, 3 , 6-8.

Chen, Y. B. (2006). Dream of great power in South-Asia and development of higher education of India. Higher Education Development and Evaluation, 2, 31-34.

Duan, C. Y., \& Li, X. H. (2014). “The Belt and Road Initiative” and strategy of development of higher education in Yunnan. The Journal of Yunnan Administration College, 5, 133-135.

Knight, J. (1999). Issues and trends in internationalization: A comparative perspective. In S. Bond and J. P. Lemasson (Eds.), A new world of knowledge: Canadian universities and globalization (pp. 13, 294). Ottawa: International Development Research Centre.

Lepori, B., Seeber, M., \& Bonaccorsi, A. (2015). Competition for Talent. Country and organizational-level effects in the internationalization of European higher education institutions. Research Policy, 44(3), 789-802.

Lou, C. H. (2015). Logic of "The Belt and Road Initiative” and its inspiration on cooperation among China and South-Asia countries. Indian Ocean Economic and Political Review, 4, 18-31, 140.

Ran, L. F. (2013). Research on Higher Education Cooperation between Yunnan and India. Yunnan Normal University.

Zhang, Z. D. (2015). South Asia is the important area in "The Belt and Road Initiative". Retrieved from http://world.people.com.cn/n/2015/0827/c1002-27524498.html

Zhu, Y. S., Fan Q. H., \& Li P. P. (2015). Discussion on needs of higher education cooperation of Yunnan and South-Asia countries. Heihe Journal, 220(10), 4-5. 